\title{
Methods of accelerating orthodontic tooth movement: A review of contemporary literature
}

\section{Metody przyspieszania ortodontycznego przesuwania zębów - przegląd współczesnego piśmiennictwa}

\author{
Alicja Kacprzak ${ }^{1, A-D, F}$, Adrian Strzecki ${ }^{2, A-F}$ \\ ${ }^{1}$ Students' Scientific Association of Orthodontics, Medical University of Lodz, Poland \\ ${ }^{2}$ Department of Orthodontics, Medical University of Lodz, Poland \\ A - research concept and design; $\mathrm{B}$ - collection and/or assembly of data; $\mathrm{C}$ - data analysis and interpretation; \\ $D$ - writing the article; $E$ - critical revision of the article; $F$ - final approval of the article
}

Address for correspondence

Alicja Kacprzak

E-mail: alicjakacprzak94@gmail.com

Funding sources

None declared

Conflict of interest

None declared

Received on January 11, 2018

Reviewed on April 6, 2018

Accepted on May 11, 2018

DOI

$10.17219 / \mathrm{dmp} / 90989$

Copyright

@ 2018 by Wroclaw Medical University

and Polish Dental Society

This is an article distributed under the terms of the

Creative Commons Attribution Non-Commercial License

(http://creativecommons.org/licenses/by-nc-nd/4.0/)

\begin{abstract}
Technological progress and the introduction of modern therapeutic methods are constantly changing contemporary orthodontics. More and more orthodontic patients are working adults, who expect satisfactory therapeutic effects as soon as possible, increasing the importance of methods accelerating tooth movement. The aim of this study was to review the current literature regarding methods of accelerating tooth movement and reducing the duration of the active phase of therapy. The literature was collected from the PubMed and EBSCO databases using "accelerated orthodontic tooth movement" as the search key words. The methods described were categorized as conservative and surgical. The pharmacological agents used in conservative treatment, such as growth hormone, parathyroid hormone, thyroxine, and vitamin D, are especially worth mentioning. They stimulate osteoclasts to increase resorption through a variety of mechanisms. Effective methods also include physical stimuli, e.g., vibrations or photobiomodulation. Most studies describing the effects of pharmacological agents were based on animal subjects and they may therefore lack clinical relevancy. Corticotomy and its modifications based on the regional acceleratory phenomenon (RAP) might prove to be a useful augmentation of orthodontic treatment, especially in adults, including patients with periodontal disease.
\end{abstract}

Key words: orthodontics, corticotomy, accelerated tooth movement

Słowa kluczowe: ortodoncja, kortykotomia, przyspieszone przesuwanie zębów 
The dream of a beautiful smile is currently not difficult to fulfill, as interdisciplinary treatment involving prosthetic, surgical, periodontal, and orthodontic procedures makes successful esthetic effects possible in the majority of cases. Among these methods, orthodontics have a fundamental disadvantage: prolonged therapy time. Depending on the kind and severity of the defect, as well as the general condition of the patient, comprehensive treatment lasts on average close to 2 years. ${ }^{1}$ This has a negative impact on the patient's compliance with braces requiring strict control of meals consumed, special attention to hygiene, and regular appointments at the orthodontist's office. On the clinical level, long-term therapy may lead to iatrogenic complications, including demineralization of enamel, tooth decay, inflammation and recession of gums, damage to the periodontium, or root resorption. ${ }^{2}$ In light of contemporary literature, using increased force to accelerate the movement of teeth is discouraged due to possible hyalinization of the periodontal fibers and undermining resorption, leading to delayed movement. ${ }^{3}$ It is therefore necessary to affect the surroundings of the tooth that ensure its stable position in the neutral zone - the alveolar bone. Tooth movement takes place with the simultaneous cooperation of osteoclasts in the pressure zone (which leads to resorption) and osteoblasts in the pulling zone (the apposition process). An important role is also played by periodontal ligaments, which, while acting as a "force absorber", also play the role of specific receptors associated with the sympathetic system. ${ }^{3}$ Methods of accelerating tooth movement are based on stimulating biological tissue response, i.e., enhanced metabolism and accelerated bone remodeling. On the basis of the level of invasiveness, the methods encountered in the scientific literature can be divided into conservative methods and those based on surgical intervention.

\section{Conservative methods}

\section{The application of pharmacological agents}

At the cellular level, the predominance of osteoclast activity over osteoblasts is responsible for bone resorption. It occurs as a result of the intensification of the inflammatory process in the periodontal and connective tissue of the gum. Mature osteoclasts can be stimulated by pro-inflammatory signals coming from periopathogens (LPS Gram-negative bacteria), fibroblasts (MMP-1, MMP-2, MMP-3), macrophages (IL-1 $\beta$, IL-6, TNF $\alpha$, PGE2), or Th lymphocytes (IL-6, IL-11, IL-17). Another pathway of bone resorption is based on the mechanism of osteoblast and cell-precursor differentiation towards osteoclasts. This is an effect of the nuclear factor kappa $B$ receptor (RANK) system and the receptor activator of nuclear factor kappa-B ligand (RANKL) competing with osteoprotegerin (OPG). ${ }^{4}$

\section{Growth hormone}

Growth hormone $(\mathrm{GH})$, also called somatotropin, is secreted by the anterior lobe of the pituitary gland. It has a stimulating effect on bone growth and remodeling, and a deficiency results in pituitary dwarfism. The action of $\mathrm{GH}$ is based directly on increases in the proliferation and differentiation of osteoblasts, as well as on induction of protein synthesis and mineralization. ${ }^{5}$ Ribeiro et al. assessed the modifying effect of growth hormone on the pace of tooth movement during experimental orthodontic treatment in rats. ${ }^{6}$ In their study, individuals from the experimental group were administered daily subcutaneous doses of growth hormone of $\approx 0.033 \mathrm{mg} / \mathrm{kg}$, analogous to the dose used in humans. A day after the $1^{\text {st }}$ dose was administered, a nickel-titanium spring was fixed between the incisor and the right $1^{\text {st }}$ molar, exerting a force of $30 \mathrm{~g}$. Growth hormone accelerated bone resorption (in the experimental group the highest number of osteoclasts was recorded as early as on the $3^{\text {rd }}$ day, which was twice as high as in the control group on day 7), but it also delayed angiogenesis. This suggested that the activation of a device should be less frequent after GH administration. There are even recommendations to begin orthodontic therapy 12-24 months after GH administration, because only then will somatotropin stimulate the process of bone formation. ${ }^{7}$ As $\mathrm{GH}$ reduces the synchronization between resorption and bone apposition, this is not a method of high potential clinical relevancy.

\section{Parathormone}

Parathormone $(\mathrm{PTH})$ is a compound secreted by the parathyroid gland which binds to receptors on osteoblasts, activating them and leading to the expression of insulin-like growth factor 1 (IGF-1; somatomedin). This results in the proliferation of osteoblasts and, with the participation of the RANK ligand, osteoclast activation. ${ }^{8}$ Depending on the frequency of administration, PTH may stimulate bone formation (intermittent therapy) or its resorption (exposure longer than 1-2 years). 9 Two 12-day studies in rats confirmed that intermittent administration of PTH accelerated the mesialization of the $1^{\text {st }}$ molar 1.6 times after administration of a dose of $0.25 \mu \mathrm{g} / 100 \mathrm{~g}$ b.w. into the subperiosteal area and 1.4 times as a result of subcutaneous administration of $4 \mu \mathrm{g} / 100 \mathrm{~g}$ m.c. ${ }^{10,11}$ However, another study by the same authors does not confirm the efficacy of intermittent therapy. ${ }^{12}$ Long-term research on the superiority of this method over other protocols is needed, as well as clinical trials. Nevertheless, it is important to consider chronic PTH intake when planning orthodontic treatment, e.g., in cases of severe osteoporosis. ${ }^{9,13}$ 


\section{Vitamin D}

Another agent that may affect tooth movement is vitamin D. 1,25-dihydroxycholecalciferol is the most active metabolite of this vitamin. It mainly has an anabolic effect on the bone tissue (to a small extent also catabolic). ${ }^{14}$ Similarly to PTH, sub-periosteal administration of vitamin $\mathrm{D}$ enhances the activity and proliferation of osteoblasts. ${ }^{15}$ These properties prompted researchers to design animal experiments attempting to modify the course of orthodontic treatment. Collins et al. used calcitriol dissolved in DMSO (dimethylsulfoxide) - a compound that readily penetrates cell membranes, as well as has a high solubility coefficient for vitamin D) - administered daily into the periosteum. ${ }^{16,17}$ After 3 weeks, the retraction range of the canines was $60 \%$ higher compared to the control group. Other researchers came to similar conclusions, this time testing the action of this vitamin on rats. They noticed an increased number of both osteoclasts and osteoblasts. ${ }^{18-20}$ Kawakami and Takano-Yamamoto emphasized the continuation of intensified remodeling during the retention period as well. ${ }^{19}$ In turn, Kale et al. observed that distalization of the maxillary incisors increased by $23 \% .{ }^{20}$ In a few clinical trials, acceleration of orthodontic tooth movement was also demonstrated. ${ }^{21}$ After a daily oral dose of $0.25 \mu \mathrm{g}$ of vitamin $\mathrm{D}$, the mean difference in the retraction movement between the experimental group and the control group (who underwent orthodontic therapy without supplementation) was $1 \mathrm{~mm} / 60$ days. However, the use of a very low dose of the supplement in the study appears to be questionable (10 IU vs the daily recommendations of 1000-2000 IU).

\section{Thyroxine}

Thyroxine administration is a recommended form of hypothyroidism treatment. It increases bone remodeling and stimulates resorption, which contributes to a decrease in bone density. This is probably due to the increased concentration of interleukin 1 (IL-1), which stimulates the formation of osteoclasts and the resorption process. ${ }^{14}$ Animal studies confirm accelerated tooth movement after administration of this substance. ${ }^{22-24}$ Seifi et al. observed $0.45 \mathrm{~mm}$ of movement after 21 days in their experimental group, compared to $0.23 \mathrm{~mm}$ in the control group. ${ }^{22}$ Additionally, they detected cumulative effects of concomitant administration of thyroxine and prostaglandine E2 $(0.74 \mathrm{~mm}$ of movement). However, Shirazi et al. noticed much less root resorption after thyroxine-assisted orthodontic treatment. ${ }^{23}$ Despite the lack of clinical trials, the presence of metabolic diseases related to the thyroid gland should be taken into consideration when planning orthodontic treatment. In cases of hypothyroid- ism it is recommended to activate the device less frequently, whereas for patients with hyperthyroidism, a longer retention period is recommended. ${ }^{24}$

\section{Beta 2-adrenergic agonist}

There is a very specific periodontal microenvironment between the tooth and the bone that requires further description. It consists of collagen fibers, cells and tissue fluid acting as a force absorber. The ligaments are strongly innervated: they contribute to the transmission of pain, modification of the immune response and bone remodeling. ${ }^{25}$ During orthodontic treatment mechanical force acting on the tooth is transmitted to these ligaments. Periodontal cells stimulate the biological response (e.g., by increasing the amount of Y-neuropeptide-containing fiber, substance $\mathrm{P}$ or calcitonin gene-related peptide). ${ }^{26}$ This is confirmed by the impossibility of moving ankylotic teeth, which are deprived of periodontal fibers due to direct connection with the bone. Periodontal ligaments are formed from the cranial neural crest differentiating in embryonic stem cells. ${ }^{27}$ Due to their origins, they express $\beta 2$-adrenergic receptors and, through the RANK receptor system, stimulate osteoblasts to undergo osteoclastogenesis. ${ }^{28}$

The available studies involving $\beta 2$-adrenergic agonists are based on direct evidence (stimulation of receptors with agonists, e.g., isoproterenol) or indirect observations (similar inhibition of the sympathetic system after using propranolol). Takeda et al., using isoproterenol, induced an osteoclastogenic response in mice. ${ }^{29}$ According to Kondo et al., by inhibiting the sympathetic system with the butaxamine, bone loss was limited and tooth movement slowed down. ${ }^{30}$ Kondo et al. also made intraperitoneal injections of propranolol, isoproterenol or (in the control group) saline solution, and blockages or stimulations confirmed their thesis. ${ }^{30}$ More invasive tests on rats were performed by $\mathrm{Cao}$ et al. ${ }^{31}$ After performing ganglionectomies of the upper cervical ganglion, they noted a decrease in osteoclast differentiation and limited tooth movement. Yamashiro et al., in an animal model of experimental tooth movement, noted a lack of significant changes in bone remodeling after transection of the lower alveolar nerve. ${ }^{26}$

In conclusion, despite the presence of many experiments related to $\beta 2$-adrenomimetics, one cannot overlook the fact that there are no clinical trials that provide significant scientific evidence.

\section{Physical stimuli}

Studies on the acceleration of teeth movement describing stimuli which increase the metabolism of tissues were investigated. The mechanisms of the most of them are not fully understood, but there is considerable evidence of their beneficial effects. 


\section{Electromagnetic fields}

Electromagnetic fields have a proven effect on cell membrane permeability. ${ }^{3}$ They can be divided into static magnetic fields (SMF) and pulsed electromagnetic fields (PEMF). Both types have been used in general medicine for many years. A SMF can contribute to the healing process after an osteotomy, can stimulate bone remodeling, or prevent bone volume decrease after surgical intervention or implantation. ${ }^{32-34}$ In the field of orthodontics, it has been used for many years as an element supporting active therapy or even as an independent procedure. It may be of certain clinical benefit during space closure, intrusion, forced extrusion of impacted teeth, and palatal expansion. ${ }^{35-38}$ An analysis of the few available animal studies concludes that in order to accelerate tooth movement, a field with a flux density of $460 \mathrm{mT}$ should be used. ${ }^{39,40}$ Sakata et al. came to this conclusion analyzing the previous experiment of Tengku et al., who, while using the intensity of $10 \mathrm{mT}$, did not observe clinically satisfactory results. ${ }^{39,40}$ A PEMF, by stimulating osteoblasts to proliferate and differentiate, as well as increasing the production of alkaline phosphatase and regulating calcium metabolism, can improve the treatment of bone fractures, osteonecrosis and osteoporosis, among other things. ${ }^{32,41-45}$ According to Bassett's research, therapeutic application of magnetic fields results in the creation of cellular tension similar to that which is induced during mechanical deformation of the bone (e.g., during the movement of the teeth). ${ }^{46}$ Studies on a rat model have shown that the support of active orthodontic elements operating with a force of about $20 \mathrm{~g}$, both using a PEMF of $1.8 \mathrm{mT}$ (or $1.5 \mathrm{mT}$ ) and a Nd-Fe-B magnet (neodymium), increases the distance a tooth can be moved. ${ }^{47,48}$ Stark and Sinclair and Showkatbakhsh et al. also confirmed the accelerating action of PEMF. ${ }^{32,49}$ The clinical trial by Showkatbakhsh et al., assessed the distalization of the canine after $1^{\text {st }}$ premolar extraction, using a removable PEMF-generating device with an intensity of $0.5 \mathrm{mT}$ and a frequency of $1 \mathrm{~Hz} \cdot{ }^{49}$ After 6 months, the difference in movements between the test and control groups was $1.57 \pm 0.83 \mathrm{~mm}$. Dogru et al. performed an experiment on rats comparing a PEMF to a sinusoidal field. ${ }^{48}$ In both cases, they observed positive effects. However, the authors pointed out that due to differences in size and physiology, predicted results on the human body should be extrapolated with caution. Information regarding the lag phase in orthodontic tooth movement (the phase of clearing hyalinized fibers from the pressure zone) is also important. It can be hypothesized that electromagnetic field therapy can shorten the lag phase (due, among other things, to earlier formation and removal of hyalinized tissue). ${ }^{39,40,47}$

\section{Vibrations}

Rubin et al. have proven that vibrations increase the remodeling rate and the overall reconstruction of the long bones - a phenomenon used in the prevention of osteoporosis. ${ }^{50}$ In addition, by comparing the effects of cyclic and static forces in experiments on animal models (cranial sutures and the periosteum of the long bones), an improvement in bone formation and an increase in orthodontic tooth movement was observed. ${ }^{51-53}$ Initial clinical trials have shown promising results. Dubravko et al. used the AcceleDent device (OrthoAccel Technologies, Inc., Bellaire, USA) to generate a vibration of $0.25 \mathrm{~N}$ and a frequency of $30 \mathrm{~Hz} .{ }^{54}$ It was possible to accelerate the distalization of canines with skeletal anchorage by $48.1 \%$ compared to the control group ( $1.16 \mathrm{~mm}$ vs $0.79 \mathrm{~mm} / \mathrm{month})$. Other reports have also confirmed the accelerating effect of vibrations. ${ }^{55}$ This time, the source of the stimuli was electric toothbrush massage for $15 \mathrm{~min}$ a day (a frequency of $125 \mathrm{~Hz}$ ). Within 3 months, a $2.85 \mathrm{~mm}$ distal axial movement of the canines was obtained $(37.7 \%$ greater than in the control group). Those authors additionally investigated the concentration of IL- $1 \beta$ in fluid collected from the gingival pocket, which, as a factor stimulating the expression of RANKL, can be a good indicator of the effectiveness of orthodontic movement. ${ }^{56,57}$ On the pressure side, the concentration of the cytokine in the study group was on average more than 6 times higher than in the fluid collected from the control group. Contrary to expectations, acceleration was not confirmed by studies in mice in which orthodontic forces were applied to the $1^{\text {st }}$ molars and low frequency vibrations $(5,10$ and $20 \mathrm{~Hz})$ were used. ${ }^{58}$ Furthermore, the latest randomized clinical trials call into question the chances of significantly shortening the time of orthodontic treatment by administering vibrations..$^{59,60}$

\section{Photobiomodulation}

This technique can be characterized by a very limited invasiveness. It involves the exposure of tissues to the effects of red light of a therapeutic wavelength (600-1200 nm) ${ }^{61}$ These wavelengths reduce absorption of the light by hemoglobin and water and allow it to reach the deeper soft tissue and the alveolar bone. ${ }^{62}$ The resulting stimulation may have potentially positive effects on the production of adenosine triphosphate (ATP). ${ }^{63}$ On the other hand, increasing the activity of cells leads to increased bone metabolism in situ, which creates favorable conditions for the movement of teeth. ${ }^{64}$ Therapy with light can be divided into 2 basic types: low-intensity lasers (LIL), producing coherent light, and light-emitting diodes (LED), which are sources of incoherent light. ${ }^{65}$ There are no publications regarding the superiority of one above the other. What is more, most authors agree that the cellular response depends primarily on the wavelength and 
the dose of light, not on its source. ${ }^{66}$ Only Fujita et al. noted more favorable results in LIL therapy, and Vinck et al. found that an LED source creates more favorable conditions for cell growth in green light. ${ }^{67,68}$ Numerous studies on this subject can be found in the literature, on both animal and clinical models. Most of them indicate a significant increase in the speed of tooth movement. In these studies gallium-aluminum-arsenide (Ga-Al-As) lasers were used, and the length of light wave was on average $820 \mathrm{~nm}$. The challenge was to determine the optimal energy dose. ${ }^{61,70,72,75}$ Goulart et al. achieved acceleration as a result of a combined dose of $5.25 \mathrm{~J} / \mathrm{cm}^{2}$, but noted that increasing it to $35 \mathrm{~J} / \mathrm{cm}^{2}$ could have the opposite effect. ${ }^{69}$ This thesis was confirmed by several researchers, including some studies applying irradiations of $100 \mathrm{~mW} \cdot{ }^{61-70}$ Animal studies have adopted a methodology focusing on determining remodeling efficiency, the RANK/RANKL system, and the expression of fibronectin and type I collagen. ${ }^{67,71,72}$ In addition to standard tooth movements, Saito and Shimizu were able to accelerate bone regeneration after suture opening during expansion of the palate in rats. ${ }^{73}$ Youssef et al., after 6 months of research on a group of 15 adults, achieved an almost 2-fold acceleration of canine retraction. ${ }^{70}$ Nahas et al. investigated the effects of the OrthoPulse device (Biolux Research Ltd., Vancouver, Canada) in patients with Little's irregularity index in the range of $2-10 \mathrm{~mm} .{ }^{61}$ Satisfactory results were obtained in the research group after an average of 68.3 days (compared with 87.8 days in the control group), which shortened the treatment time by $22 \%$. Acceleration has also been reported in a few randomized clinical trials. ${ }^{74-76}$ Nevertheless, Marquezan et al., during an experiment on an animal model, despite an increased number of osteoclasts on the pressure zone side, did not notice an increased dental shift macroscopically. ${ }^{77}$ Chung et al. came to a similar conclusion after observing 11 patients for 3 months. ${ }^{79}$ To sum up, due to the differences in the protocols of the experiments conducted, further research is needed, focusing, among other things, on harmonizing the radiation dose.

\section{Clear aligners and self-ligating brackets}

In the literature, only a few studies can be found analyzing the acceleration of the movement of teeth using clear aligners and self-ligating brackets. It should also be noted that research based on histological evidence is lacking. Conclusions can be drawn based only on the differences in therapy duration and cases assessed using various indices, such as the peer assessment rating (PAR) or the objective grading system (OGS). ${ }^{79,80}$ $\mathrm{Gu}$ et al. found the Invisalign system (Align Technology Inc., San Jose, USA) to be advantageous in correcting minor orthodontic defects; the duration of treatment with the same effects was 30\% (5.7 months) shorter compared to fixed braces. ${ }^{79}$ Buschang et al. reached similar conclusions: in a study of 150 patients with incisor crowding under $5 \mathrm{~mm}$ (the study group), they noted that the duration of therapy was reduced by 5.5 months. ${ }^{81}$ However, despite shorter treatment and less frequent visits, they point out that aligner therapy is much more expensive and requires more experience. On the other hand, Hennessy et al. did not notice a difference between the length of the treatment of mandible incisor crowding with the Invisalign system and with a fixed labial appliance. ${ }^{82}$ In summary, the use of clear thermoplastic aligners, despite their presence and growing popularity in orthodontic clinics, requires further research in terms of accelerating the movement of teeth.

Self-ligating brackets are also worth mentioning. The $1^{\text {st }}$ brackets of this type were created by Stolzenberg over 70 years ago. ${ }^{83}$ The aim was to reduce the friction between the arch and the bracket, which is increased by ligatures (both elastic and metallic). According to some researchers, reducing it improved the effectiveness of the "sliding mechanism" used during tooth rotation, correction of angulation and closing spaces. ${ }^{84}$ It does not affect bone remodeling, but only changes the distribution of forces that the orthodontist uses during treatment. In addition, despite manufacturers' assurances of shorter treatment times, numerous studies have reported the opposite, detecting no significant differences between the duration of active therapy with the use of conventional and self-ligating devices. ${ }^{85,86}$

\section{Surgical methods}

Surgical methods are more invasive, but also significantly broaden the scope of therapeutic options. They are used primarily when the remaining methods are insufficient, i.e., mainly after the period of growth is finished. They are characterized by surgical intervention to the bone tissue, which is more susceptible to the action of orthodontic forces while undergoing remodeling after traumatization.

\section{Corticotomy}

The aim of corticotomy is to cut the cortical layer of alveolar bone in order to induce local temporary osteopenia. Over the last several decades, it has undergone numerous modifications. The origins of the method date back to the end of the $19^{\text {th }}$ century; however, Köle, who discussed the procedure in 1959, is considered the pioneer of corticotomy. ${ }^{87,88}$ According to his claims, cortical bone is the main obstacle to the orthodontic movement of teeth. This theory, referring to osteotomy, was to a certain extent rejected in 1983, when Frost discovered the regional acceleratory phenomenon (RAP), and in 1994 Yaffe et al. introduced this concept to periodontal lit- 


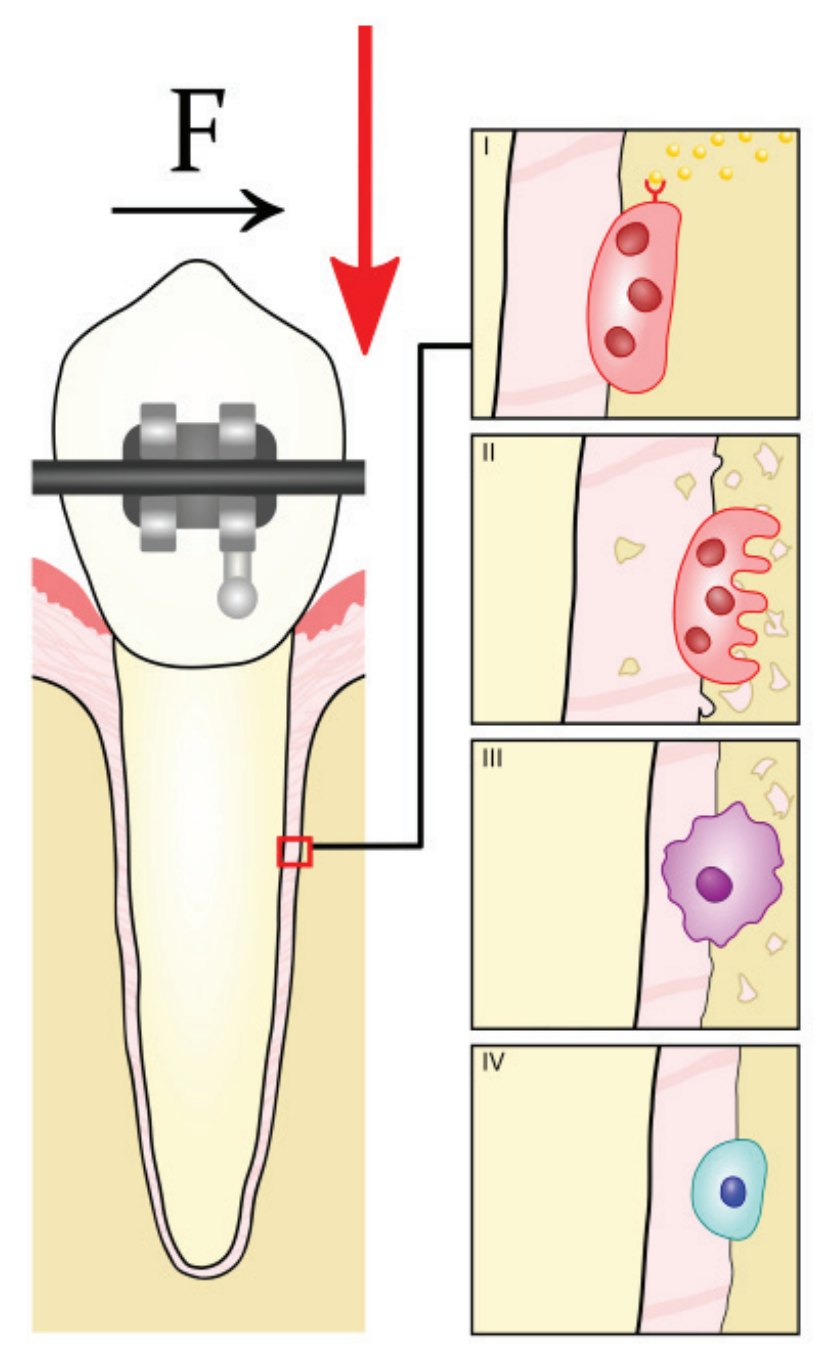

Fig. 1. The regional acceleratory phenomenon (RAP) - a phenomenon described by $\mathrm{H}$. Frost in 1983, involving the temporary reduction of bone density as a result of harmful stimulus. I - The release of pro-inflammatory cytokines activating osteoclast progenitor cells as a result of harmful stimuli. II - Bone resorption caused by the action of mature osteoclasts. Bone density decreases by 10-50 times, making tissue much more susceptible to the action of orthodontic forces. III - Arrangement of the resorbed tissue by macrophages. IV - The inflow of osteoblasts. Bone remineralization with teeth in new positions after 4 months

erature (Fig. 1). ${ }^{89,90}$ Small harmful stimuli (such as shallow bone incisions) activate the RANK/RANKL system. In "weakened" bone tissue, 10-50 times faster remodeling is expected. This effect lasts for about 4 months (though it can last up to 6-24 months), with peak efficiency reached 1 or 2 months after surgery. ${ }^{91}$ Due to the nature of the surgery, which involves a high risk of infection, antibiotic protection is vital. Only local anesthesia is required. The field of the procedure depends on the defect: vertical incisions are made between the roots of the teeth, horizontally, 2-3 mm above the apices, in order not to damage the bundles. The advantage of the method lies in the creation of a more stable anchorage, not involving teeth/ arches in the procedure. The brackets of the fixed appliance are bonded before the surgery. The cuts, after ear- lier retraction of the muco-periosteal flap, can be made with traditional rotational tools or a piezoelectric knife. Dibart et al. recommend the use of the latter, due to limited traumatization of tissues, greater precision of execution, and more extensive bone demineralization, which induces prolonged RAP. ${ }^{92}$ To avoid interfering with the bone remodeling process, non-steroidal anti-inflammatory drugs (NSAIDs) should not be administered. Initially (in the first 3-7 days) the pain can severely affect the patient's well-being. Tooth brushing should be neglected for a week. An alternative is to rinse the mouth with an antiseptic solution (e.g., chlorhexidine). After this period, the $1^{\text {st }}$ activation of the braces can be performed. It is important that during the demineralization of the bones, the patient appears regularly for frequent visits. ${ }^{92}$

\section{Periodontally accelerated osteogenic orthodontics}

Described by Wilcko et al. in 2001, the technique referred to as periodontally accelerated osteogenic orthodontics (PAOO) or accelerated osteogenic orthodontics (AOO) is a combination of conventional corticotomy with the implantation of bone graft material. ${ }^{93}$ After analyzing high-resolution computed tomography (CT) scans, Wilcko et al. observed the process of remodeling remineralization and demineralization of the bone and demonstrated its relationship with the RAP, as described earlier. ${ }^{93}$ After retraction of the muco-periosteal flap and incisions in selected areas, allogenic frozen and dried material is placed in the scars. It is very important that it is fully biocompatible. Otherwise, only the extension of the epithelial attachment can be observed, leading to the accumulation of bacteria, which in turn may result in abscess formation and bone loss. ${ }^{94}$ Insertion of the material allows bone density and mass to increase. This is particularly important in adults, who have much lower regenerative bone capacity than children. The main goal is to surround the teeth on each side, while eliminating fenestration and bone dehiscence. This increases the possible range of tooth movement, the apical base and the arch envelope, and minimizes gum recessions, relapses and the need for extraction. ${ }^{95}$ One indication is the presence of shortened roots, which could become shorter during traditional treatment. ${ }^{96}$ Wilcko et al. presented many cases demonstrating the effectiveness of the method in accelerating the movement of teeth while improving the condition of periodontal tissues. ${ }^{97,98}$

\section{Piezocision}

To initiate the RAP phenomenon, one needs to perform a cut to the cortical layer of bone. In the traditional technique, this stage is preceded by the detachment of the muco-periosteal flap. This increases the risk of discomfort and postoperative pain. Park et al. and Kim et al. proposed 
performing the procedure without the flap retraction, but directly through the gum. ${ }^{99,100}$ An alternative combining limited invasiveness, enhanced precision and treatment of periodontal problems is piezosurgery (the piezocision technique), described in 2009 by Dibart et al. ${ }^{101}$ It combines cuts in the bone through the gingiva with a piezoelectric knife to create of submucosal tunnels for bonesubstitute material. The orientation incisions are made with a scalpel, then a piezoelectric knife is used with a marker indicating the working depth (according to the author, it is necessary to go through the entire cortical layer and reach the cancellous bone to stimulate RAP). Particular caution should be exercised in the area of interdental papillae and between roots located close to each other. Tunneling can be performed in areas of gingival recession, dehiscences or fenestrations. In the anterior part of the mandible, due to the small width of the teeth, incisions between the lateral and central incisors can be omitted. Active elements of the device are activated every 2 weeks, starting 2 weeks after the procedure.

\section{Micro-osteoperforations}

This is another treatment modality based on the RAP. ${ }^{102}$ The goal is to further minimize soft tissue damage. Perforations are made in the bone through the mucous membrane, with the aim of accelerating orthodontic movement. Micro-osteoperforations can also be combined with standard corticotomy or the PAOO technique. The device used during the treatment was designed by Propel Orthodontics (Ossing, USA). ${ }^{103}$ It is intended for single use only. It perforates both the attached gingiva and the mucous membrane. Clinically, the use of micro-osteoperforations significantly increases the expression of cytokines, which leads to a $60 \%$ shorter treatment time compared to a control group, and 2.3 times faster retraction of canines. ${ }^{102}$ The procedure itself is described as effective, convenient, and less invasive than standard corticotomy. ${ }^{104}$

Corticotomy and other attempts at surgical acceleration of tooth movement are documented in a large number of scientific publications. Despite the different levels of invasiveness, they have similar effectiveness, which was confirmed in a comparative study by Librizzi et al. ${ }^{105}$ It can be assumed that this is the effect of the same mechanism of action (inducing the RAP). Experiments conducted on an animal model show both a shorter therapy time and increased remodeling occurring within the cancellous bone. ${ }^{106-108}$ Similar results were obtained during the treatment of mild crowding (a study on 24 patients resulted in a $47 \%$ shorter treatment time), orthodontic extrusion of palatally impacted canines (6 patients) and retroinclination of upper incisors with sufficient bone support. ${ }^{109-111}$ Al-Naoum et al., in a group of 30 patients, obtained an average speed of $0.74 \mathrm{~mm} /$ week (compared to $0.2 \mathrm{~mm} /$ week on the control side) during retraction of canines. ${ }^{112}$ The potential usefulness of corticotomy in the treatment of post-traumatic ankylosis is also worth considering. Małyszko et al. published a case of post-traumatic intrusion of tooth 11 complicated with ankylosis and resistant to other methods of traditional orthodontic treatment. ${ }^{113}$ The application of bone incisions with the intraocular luxation resulted in a positive effect, i.e., tooth extrusion. The role of corticotomy in clinical orthodontics seems to be constantly growing and is currently one of the most frequently used methods to shorten the time of orthodontic treatment.

\section{Combined methods}

Considering the different mechanisms of action of conservative and surgical methods, the question arises: Would the combination of both prove even more efficient? Referring to this hypothesis, Kim et al. conducted a study combining cortical bone incision (also referred to as corticision) and radiation. ${ }^{114}$ The experiment involved 12 dogs divided into 4 groups: a control group (only orthodontic force was used), a group undergoing photobiostimulation, a group undergoing surgical treatment, and a group in which both of these methods were implemented. In the groups involving the surgical procedure, incisions were made near the $2^{\text {nd }}$ maxillary premolars (for the purpose of their mesialization after the extraction of the $1^{\text {st }}$ premolars). A diode laser with a wavelength of $808 \mathrm{~nm}$ was used as the source of photobiostimulation. Contrary to expectations, the group covered by both treatment methods showed less acceleration than the groups undergoing each treatment separately. Moreover, within 8 weeks after the procedure, the dental movement in the group exposed to both methods was comparable to the control group (in which only orthodontic forces were used). Considering the regenerative effect of light irradiation, it can be assumed that the laser significantly accelerated bone healing and thus led to the elimination of the RAP. The available literature also describes 2 cases in which corticotomy and Smiletech polyvinyl overlays (Ortodontica Italia, Rome, Italy) were used. Cassetta et al. described the therapy of 2 patients with moderate crowding (the $1^{\text {st }}$ with class I, the $2^{\text {nd }}$ with class II). ${ }^{115,116}$ The treatment was completed with a satisfactory effect after 2 months (in the class I patient) and after 8 months (in the class II patient). However, attention should be paid to the low power of scientific evidence (no control group; only a case report) and the possible bias of the conducted study.

\section{Conclusions}

The contemporary literature presents many methods of accelerating tooth movement during orthodontic treatment, but a significant number of them, especially those using pharmacological agents, are supported by rather limited 
scientific evidence due to the fact that randomized clinical trials are rarely encountered. The methods using physical stimuli, in spite of the larger number of published trials, can prove difficult to apply in everyday practice due to the use of expensive and specialized equipment and the need for regular and repeated administration of specific agents. Surgical methods are currently the most soundly evidenced, and could be described as methods of documented efficacy. Unfortunately, they are associated with significant (though constantly diminishing) invasiveness, exposing the patient to additional stress and postoperative pain.

\section{References}

1. Tsichlaki A, Chin SY, Pandis N, Fleming PS. How long does treatment with fixed orthodontic appliances last? A systematic review. Am J Orthod Dentofacial Orthop. 2016;149:308-318.

2. Szymańska-Kubal D. Selected complications of orthodontic treatment with fixed and removableappliances [in Polish]. NowaStomatol. 1999;4:1-2:31-40.

3. Proffit WR, Fields HW, Sarver DM. The biologic basis of orthodontic therapy. In: Komorowska A, ed. Contemporary Orthodontics [in Polish]. Wrocław, Poland: Elsevier Urban\&Partner; 2016;2:7-9.

4. Konopka T. Etiopathogenesis of periodontal diseases. In: Górska R, Konopka T, eds. Contemporary Periodontology [in Polish]. Otwock, Poland: Med Tour Press International; 2013:94-95.

5. Marcus R. Skeletal effects of growth hormone and IGF-I in adults. Horm Res. 1997;48(Suppl 5):60-64.

6. Ribeiro JS, Maciel JV, KnopLA, Machado MÂ, Grégio AM, Camargo ES. Effect of growth hormone in experimental tooth movement. Braz Dent J. 2013;24:503-507.

7. Simpson H, Savine R, Sönksen P, et al.; GRS Council. Growth hormone replacement therapy for adults: Into the new millennium. Growth Horm IGF Res. 2002;12:1-33.

8. Dobnig H, Turner RT. Evidence that intermittent treatment with parathyroid hormone increases bone formation in adult rats by activation of bone lining cells. Endocrinol. 1995;136:3632-3638.

9. Esbrit P, Alcaraz MJ. Current perspectives on parathyroid hormone (PTH) and PTH-related protein (PTHrP) as bone anabolic therapies. Biochem Pharmacol. 2013;85:1417-1423.

10. Soma S, Matsumoto S, Higuchi $Y$, et al. Local and chronic application of PTH accelerates tooth movement in rats. J Dent Res. 2000;79:1717-1724.

11. Li F, Li G, Hu H, Liu R, Chen J, Zou S. Effect of parathyroid hormone on experimental tooth movement in rats. Am J Orthod Dentofacial Orthop. 2013;144:523-532.

12. Soma S, Iwamoto M, Higuchi Y, Kurisu K. Effects of continuous infusion of PTH on experimental tooth movement in rats. J Bone Miner Res. 1999;14:546-554.

13. Diravidamani K, Sivalingam SK, Agarwal V. Drugs influencing orthodontic tooth movement: An overall review. J Pharm Bioallied Sci. 2012;4(Suppl 2):299-303.

14. Kouskoura T, Katsaros C, von Gunten S. The potential use of pharmacological agents to modulate orthodontic tooth movement (OTM). Front Physiol. 2017;8:67.

15. Reichel H, Koeffler HP, Norman AW. The role of the vitamin D endocrine system in health and disease. NEngl J Med. 1989;320:980-991.

16. Collins MK, Sinclair PM. The local use of vitamin D to increase the rate of orthodontic tooth movement. Am J Orthod Dentofacial Orthop. 1988;94:278-284.

17. Wood DC, Wood J. Pharmacologic and biochemical considerations of dimethyl sulfoxide. Ann NY Acad Sci. 1975;243:7-19.

18. Takano-Yamamoto T, Kawakami M, Kobayashi Y, Yamashiro T, Sakuda M. The effect of local application of 1,25-dihydroxycholecalciferol on osteoclast numbers in orthodontically treated rats. J Dent Res. 1992;71:53-59.

19. Kawakami M, Takano-Yamamoto T. Local injection of 1,25-dihydroxyvitamin D3 enhanced bone formation for tooth stabilization after experimental tooth movement in rats. $J$ Bone Miner Metab. 2004;22:541-546.
20. Kale S, Kocadereli I, Atilla P, Aşan E. Comparison of the effects of 1,25 dihydroxycholecalciferol and prostaglandin E2 on orthodontic tooth movement. Am J Orthod Dentofacial Orthop. 2004;125:607-614.

21. Blanco JF, Diaz R, Gross H, Rodríguez N, Hernandez LR. Efecto de la administración sistémica del 1,25 Dihidrxicolecalciferol sobre la velocidad del movimiento ortodóncico en humanos. Estudio Clínico Revista Odontos. 2001;8:13-21.

22. Seifi M, Hamedi R, Khavandegar Z. The effect of thyroid hormone, prostaglandin E2, and calcium gluconate on orthodontic tooth movement and root resorption in rats. J Dent (Shiraz). 2015;16(Suppl 1):35-42.

23. Shirazi M, Dehpour AR, Jafari F. The effect of thyroid hormone on orthodontic tooth movement in rats. J Clin Pediatr Dent. 1999;23:259-264.

24. Verna C, Dalstra M, Melsen B. The rate and the type of orthodontic tooth movement is influenced by bone turnover in a rat model. Eur J Orthod. 2000;22:343-352.

25. Deguchi T, Yabuuchi T, Ando R, Ichikawa H, Sugimoto T, TakanoYamamoto $\mathrm{T}$. Increase of galanin in trigeminal ganglion during tooth movement. J Dent Res. 2006;85:658-663.

26. Yamashiro T, Fujiyama K, Fujiyoshi Y, Inaguma N, Takano-Yamamoto T. Inferior alveolar nerve transection inhibits increase in osteoclast appearance during experimental tooth movement. Bone. 2000;26:663-669.

27. Dupin E, Sommer L. Neural crest progenitors and stem cells: From early development to adulthood. Dev Biol. 2012;366:83-95.

28. Takeuchi T, Tsuboi T, Arai M, Togari A. Adrenergic stimulation of osteoclastogenesis mediated by expression of osteoclast differentiation factor in MC3T3-E1 osteoblast-like cells. Biochem Pharmacol. 2001;61:579-586.

29. Takeda S, Elefteriou F, Levasseur R, et al. Leptin regulates bone formation via the sympathetic nervous system. Cell. 2002;111:305-317.

30. Kondo M, Kondo H, Miyazawa K, Goto S, Togari A. Experimental tooth movement-induced osteoclast activation is regulated by sympathetic signaling. Bone. 2013;52:39-47.

31. Cao H, Kou X, Yang R, et al. Force-induced Adrb2 in periodontal ligament cells promotes tooth movement. J Dent Res. 2014;93:1163-1169.

32. Stark TM, Sinclair PM. Effect of pulsed electromagnetic fields on orthodontic tooth movement. Am J Orthod Dentofacial Orthop. 1987;91:91-104.

33. Kotani $H$, Kawaguchi $H$, Shimoaka $T$, et al. Strong static magnetic field stimulates bone formation to a definite orientation in vitro and in vivo. J Bone Miner Res. 2002;17:1814-1821.

34. Yan QC, Tomita N, Ikada Y. Effects of static magnetic field on bone formation of rat femurs. Med Eng Phys. 1998;20:397-402.

35. Kawata T, Hirota K, Sumitani K, et al. A new orthodontic force system of magnetic brackets. Am J Orthod Dentofacial Orthop. 1987;92:241-248.

36. Hwang HS, Lee KH. Intrusion of overerupted molars by corticotomy and magnets. Am J Orthod Dentofacial Orthop. 2001;120:209-216.

37. Oki M, Yamamoto Y, Yasunaga T, Shiina R, Kawano S, Nakasima A. A treatment method for bringing an impacted tooth into the dental arch using fine magnets: Measurements of traction force using NdFeB magnets. Nihon Kyosei Shika Gakkai Zasshi. 2001;60:104-111.

38. Vardimon AD, Graber TM, Voss LR. Stability of magnetic versus mechanical palatal expansion. Eur J Orthod. 1989;11:107-115.

39. Sakata M, Yamamoto Y, Imamura N, Nakata S, Nakasima A. The effects of a static magnetic field on orthodontic tooth movement. J Orthod. 2008;35:249-254.

40. Tengku BS, Joseph BK, Harbrow D, Taverne AA, Symons AL. Effect of a static magnetic field on orthodontic tooth movement in the rat. Eur J Orthod. 2000;22:475-487.

41. De Mattei M, Caruso A, Traina GC, Pezzetti F, Baroni T, Sollazzo V. Correlation between pulsed electromagnetic fields exposure time and cell proliferation increase in human osteosarcoma cell lines and human normal osteoblast cells in vitro. Bioelectromagnet. 1999;20:177-182.

42. Landry PS, Sadasivan KK, Marino AA, Albright JA. Electromagnetic fields can affect osteogenesis by increasing the rate of differentiation. Clin Orthop Relat Res. 1997;338:262-270. 
43. Vander Molen MA, Donahue HJ, Rubin CT, McLeod KJ. Osteoblastic networks with deficient coupling: Differential effects of magnetic and electric field exposure. Bone. 2000;27:227-231.

44. Fitzsimmons RJ, Ryaby JT, Magee FP, Baylink DJ. Combined magnetic fields increased net calcium flux in bone cells. Calcif Tissue Int 1994;55:376-380.

45. Darendeliler MA, Sinclair PM, Kusy RP. The effects of samariumcobalt magnets and pulsed electromagnetic fields on tooth movement. Am J Orthod Dentofacial Orthop. 1995;107:578-588.

46. Bassett CA. Beneficial effects of electromagnetic fields. J Cell Biochem. 1993;51:387-393.

47. Darendeliler MA, Zea A, Shen G, Zoellner H. Effects of pulsed electromagnetic field vibration on tooth movement induced by magnetic and mechanical forces: A preliminary study. Aust Dent J. 2007;52:282-287.

48. Dogru M, Akpolat V, Dogru AG, Karadede B, Akkurt A, Karadede MI. Examination of extremely low frequency electromagnetic fields on orthodontic tooth movement in rats. Biotechnol Biotechnol Equip. 2014;28:118-122.

49. Showkatbakhsh $R$, Jamilian A, Showkatbakhsh M. The effect of pulsed electromagnetic fields on the acceleration of tooth movement. World J Orthod. 2010;11:52-56.

50. Rubin C, Turner AS, Müller R, et al. Quantity and quality of trabecular bone in the femur are enhanced by a strongly anabolic, noninvasive mechanical intervention. J Bone Miner Res. 2002;17:349-357.

51. Kopher RA, Mao JJ. Suture growth modulated by the oscillatory component of micromechanical strain. J Bone Miner Res. 2003;18:521-528.

52. Peptan Al, Lopez A, Kopher RA, Mao JJ. Responses of intramembranous bone and sutures upon in vivo cyclic tensile and compressive loading. Bone. 2008;42:432-438.

53. Nishimura $M$, Chiba $M$, Ohashi $T$, et al. Periodontal tissue activation by vibration: Intermittent stimulation by resonance vibration accelerates experimental tooth movement in rats. Am J Orthod Dentofacial Orthop. 2008;133:572-583.

54. Dubravko P, Ravikumar A, Vishnu R, Gakunga PT. Cyclic loading (vibration) accelerates tooth movement in orthodontic patients: A doubleblind, randomized controlled trial. Semin Orthod. 2015;21:187-194. doi: 10.1053/j.sodo.2015.06.005

55. Leethanakul C, Suamphan S, Jitpukdeebodintra S, Thongudomporn U, Charoemratrote C. Vibratory stimulation increases interleukin-1 beta secretion during orthodontic tooth movement. Angle Orthod. 2016:86:74-80.

56. Teixeira CC, Khoo E, Tran J, et al. Cytokine expression and accelerated tooth movement. J Dent Res. 2010;89:1135-1141.

57. Ren Y, Vissink A. Cytokines in crevicular fluid and orthodontic tooth movement. Eur J Oral Sci. 2008;116:89-97.

58. Yadav S, Dobie T, Assefnia A, Gupta H, Kalajzic Z, Nanda R. Effect of low-frequency mechanical vibration on orthodontic tooth movement. Am J Orthod Dentofacial Orthop. 2015;148:440-449.

59. Woodhouse NR, DiBiase AT, Johnson N, et al. Supplemental vibrational force during orthodontic alignment: A randomized trial. J Dent Res. 2015;94:682-689.

60. Miles P, Fisher E, Pandis N. Assessment of the rate of premolar extraction space closure in the maxillary arch with the AcceleDent Aura appliance vs no appliance in adolescents: A single-blind randomized clinical trial. Am J Orthod Dentofacial Orthop. 2018;153:8-14.

61. Nahas AZ, Samara SA, Rastegar-Lari TA. Decrowding of lower anterior segment with and without photobiomodulation: A single center, randomized clinical trial. Lasers Med Sci. 2017;32:129-135.

62. Hillenkamp F, Pratesi R, Sacchi CA. Lasers in Biology and Medicine. Boston, MA: Springer; 1980;3:37-68.

63. Eells JT, Henry MM, Summerfelt P, et al. Therapeutic photobiomodulation for methanol-induced retinal toxicity. Proc Natl Acad Sci U S A. 2003;100:3439-3444.

64. Tuby H, Maltz L, Oron U. Low-level laser irradiation (LLLI) promotes proliferation of mesenchymal and cardiac stem cells in culture. Lasers Surg Med. 2007;39:373-378.

65. Vladimirov YA, Osipov AN, Klebanov GI. Photobiological principles of therapeutic applications of laser radiation. Biochemistry (MosC) 2004:69:81-90.
66. Casalechi HL, Nicolau RA, Casalechi VL, Silveira L, De Paula AM, Pacheco MT. The effects of low-level light emitting diode on the repair process of Achilles tendon therapy in rats. Lasers Med Sci. 2009;24:659-665.

67. Fujita S, Yamaguchi M, Utsunomiya T, Yamamoto H, Kasai K. Lowenergy laser stimulates tooth movement velocity via expression of RANK and RANKL. Orthod Craniofac Res. 2008;11:143-155.

68. Vinck EM, Cagnie BJ, Cornelissen MJ, Declercq HA, Cambier DC. Increased fibroblast proliferation induced by light emitting diode and low power laser irradiation. Lasers Med Sci. 2003;18:95-99.

69. Goulart CS, Nouer PR, Mouramartins L, Garbin IU, de Fátima Zanirato Lizarelli R. Photoradiation and orthodontic movement: Experimental study with canines. Photomed Laser Surg. 2006;24:192-196.

70. Youssef M, Ashkar S, Hamade E, Gutknecht N, Lampert F, Mir M. The effect of low-level laser therapy during orthodontic movement: A preliminary study. Lasers Med Sci. 2008;23:27-33.

71. Kawasaki K, Shimizu N. Effects of low-energy laser irradiation on bone remodeling during experimental tooth movement in rats. Lasers Surg Med. 2000;26:282-291.

72. Kim YD, Kim SS, Kim SJ, Kwon DW, Jeon ES, Son WS. Low-level laser irradiation facilitates fibronectin and collagen type I turnover during tooth movement in rats. Lasers Med Sci. 2010;25:25-31.

73. Saito S, Shimizu N. Stimulatory effects of low-power laser irradiation on bone regeneration in midpalatal suture during expansion in the rat. Am J Orthod Dentofacial Orthop. 1997;111:525-532.

74. Shaughnessy T, Kantarci A, Kau CH, Skrenes D, Skrenes S, Ma D. Intraoral photobiomodulation-induced orthodontic tooth alignment: A preliminary study. BMC Oral Health. 2016;16:3.

75. Üretürk SE, Saraç M, Fıratlı S, Can ŞB, Güven Y, Fıratlı E. The effect of low-level laser therapy on tooth movement during canine distalization. Lasers Med Sci. 2017;32:757-764.

76. Al-Sayed Hasan MMA, Sultan K, Hamadah O. Low-level laser therapy effectiveness in accelerating orthodontic tooth movement: A randomized controlled clinical trial. Angle Orthod. 2017;87:499-504.

77. Marquezan M, Bolognese AM, Araújo MT. Effects of two low-intensity laser therapy protocols on experimental tooth movement. Photomed Laser Surg. 2010;28:757-762.

78. Chung SE, Tompson B, Gong SG. The effect of light emitting diode phototherapy on rate of orthodontic tooth movement: A split mouth, controlled clinical trial. J Orthod. 2015;42:274-283.

79. Gu J, Tang JS, Skulski B, et al. Evaluation of Invisalign treatment effectiveness and efficiency compared with conventional fixed appliances using the Peer Assessment Rating index. Am J Orthod Dentofacial Orthop. 2017;151:259-266.

80. Djeu G, Shelton C, Maganzini A. Outcome assessment of Invisalign and traditional orthodontic treatment compared with the American Board of Orthodontics objective grading system. Am J Orthod Dentofacial Orthop. 2005;128:292-298.

81. Buschang PH, Shaw SG, Ross M, Crosby D, Campbell PM. Comparative time efficiency of aligner therapy and conventional edgewise braces. Angle Orthod. 2014;84:391-396.

82. Hennessy J, Garvey T, Al-Awadhi EA. A randomized clinical trial comparing mandibular incisor proclination produced by fixed labial appliances and clear aligners. Angle Orthod. 2016;86:706-712.

83. Stolzenberg J. The Russell attachment and its improved advantages. Int J Orthodontia Dent Child. 1935;21:837-840.

84. Harradine N. The history and development of self-ligating brackets. Semin Orthodont. 2008;14:5-18.

85. O'Dywer L, Littlewood SJ, Rahman S, Spencer RJ, Barber SK, Russell JS. A multi-center randomized controlled trial to compare a self-ligating bracket with a conventional bracket in a UK population: Part 1: Treatment efficiency. Angle Orthod. 2016;86:142-148.

86. Johansson K, Lundström F. Orthodontic treatment efficiency with self-ligating and conventional edgewise twin brackets: A prospective randomized clinical trial. Angle Orthod. 2012;82:929-934.

87. Guilford SH. Orthodontia, or Malposition of the Human Teeth, Its Prevention and Remedy. Philadelphia, PA: Spangler\&Davis; 1893.

88. Köle H. Surgical operations of the alveolar ridge to correct occlusal abnormalities. Oral Surg Oral Med Oral Pathol. 1959;12:515-529.

89. Frost $\mathrm{MH}$. The biology of fracture healing: An overview for clinicians. Part I. Clin Orthop Relat Res. 1989;248:283-293. 
90. Yaffe A, Fine N, Binderman I. Regional accelerated phenomenon in the mandible following mucoperiosteal flap surgery. J Periodontol. 1994;65:79-83.

91. Murphy KG, Wilcko MT, Wilcko WM, Ferguson DJ. Periodontal accelerated osteogenic orthodontics: A description of the surgical technique. J Oral Maxillofac Surg. 2009;67:2160-2166.

92. Mehra P. Corticotomy-facilitated orthodontics: Surgical considerations. In: Brugnami F, Caiazzo A, eds. Orthodontically Driven Corticotomy: Tissue Engineering to Enhance Orthodontic and Multidisciplinary Treatment. Hoboken, NJ: John Wiley \& Sons; 2014.

93. Wilcko WM, Wilcko T, Bouquot JE, Ferguson DJ. Rapid orthodontics with alveolar reshaping: Two case reports of decrowding. Int J Periodontics Restorative Dent. 2001;21:9-19.

94. Ericsson I, Thilander B, Lindhe J. Periodontal conditions after orthodontic tooth movements in the dog. Angle Orthod. 1978;48:210-218.

95. Murphy NC, Wilcko MT, Bissada NF, Davidovitch Z, Enlow DH, Dashe J. Orthodontic applications of alveolus decortication. In: Brugnami F, Caiazzo A, eds. Orthodontically Driven Corticotomy: Tissue Engineering to Enhance Orthodontic and Multidisciplinary Treatment. Hoboken, NJ: John Wiley \& Sons; 2014.

96. Montesinos FA, Linares TS, Pérez-Gasque BM. Accelerated Osteogenic Orthodontics ${ }^{\mathrm{TM}}$ for retreatment of a patient with diminished root length and absence of the maxillary central incisor. Saudi Dent J. 2015:27:228-234.

97. Wilcko MT, Wilko WM, Bissada NF. An evidence-based analysis of periodontally accelerated orthodontic and osteogenic techniques: A synthesis of scientific perspective. Semin Orthodont. 2008;14:305-316.

98. Wilcko WM, Wilcko MT, Bouquot JE, Ferguson DJ. Accelerated orthodontics with alveolar reshaping. J Ortho Practice. 2000;10:63-70.

99. Park YG, Kang SG, Kim SJ. Accelerated tooth movement by Corticision as an osseous orthodontic paradigm. Kinki Tokai Kyosei Shika Gakkai Gakujyutsu Taikai Sokai. 2006;48:6.

100. Kim SJ, Park YG, Kang SG. Effects of Corticision on paradental remodeling in orthodontic tooth movement. Angle Orthod. 2009;79:284-291.

101. Dibart S, Keser El. Piezocision ${ }^{\mathrm{TM}}$. In: Brugnami F, Caiazzo A, eds. Orthodontically Driven Corticotomy: Tissue Engineering to Enhance Orthodontic and Multidisciplinary Treatment. Hoboken, NJ: John Wiley \& Sons; 2014.

102. Pobanz JM, Storino D, Nicozisis J. Orthodontic acceleration: Propel alveolar micro-osteoperforation. Orthotown. 2013;5:22-25.

103. Eder SM. Accelerating tooth movement with micro-osteoperforation. Orthodontic Products. http://www.orthodonticproductsonline.com/ 2012/09/accelerating-tooth-movement-with-micro-osteoperforation/. Published September 28, 2012.

104. Alikhani M, Raptis M, Zoldan B, et al. Effect of micro-osteoperforations on the rate of tooth movement. Am J Orthod Dentofacial Orthop. 2013;144:639-648.

105. Librizzi Z, Kalajzic Z, Camacho D, Yadav S, Nanda R, Uribe F. Comparison of the effects of three surgical techniques on the rate of orthodontic tooth movement in a rat model. Angle Orthod. 2017;87:717-724.

106. Sanjideh PA, Rossouw PE, Campbell PM, Opperman LA, Buschang PH. Tooth movements in foxhounds after one or two alveolar corticotomies. Eur J Orthod. 2010;32:106-113.

107. Baloul SS, Gerstenfeld LC, Morgan EF, Carvalho RS, Van Dyke TE, Kantarci A. Mechanism of action and morphologic changes in the alveolar bone in response to selective alveolar decortication-facilitated tooth movement. Am J Orthod Dentofacial Orthop. 2011;139(Suppl 4):83-101.

108. Sebaoun JD, Kantarci A, Turner JW, Carvalho RS, Van Dyke TE, Ferguson DJ. Modeling of trabecular bone and lamina dura following selective alveolar decortication in rats. J Periodontol. 2008;79:1679-1688.

109. Charavet C, Lecloux G, Bruwier A, et al. Localized piezoelectric alveolar decortication for orthodontic treatment in adults: A randomized controlled trial. J Dent Res. 2016;95:1003-1009.

110. Fischer TJ. Orthodontic treatment acceleration with corticotomyassisted exposure of palatally impacted canines. Angle Orthod. 2007;77:417-420.
111. Lee JK, Chung KR, Baek SH. Treatment outcomes of orthodontic treatment, corticotomy-assisted orthodontic treatment, and anterior segmental osteotomy for bimaxillary dentoalveolar protrusion. Plast Reconstr Surg. 2007;120:1027-1036.

112. Al-Naoum F, Hajeer MY, Al-Jundi A. Does alveolar corticotomy accelerate orthodontic tooth movement when retracting upper canines? A split-mouth design randomized controlled trial. J Oral Maxillofac Surg. 2014;72:1880-1889.

113. Małyszko M, Szarmach I, Szarmach J, Marczuk-Kolada G, Grycz M. Post-traumatic ankylosis of the incisor, orthodontic and surgical treatment: A case report [in Polish]. Forum Ortodont. 2015;11:296-305.

114. Kim SJ, Moon SU, Kang SG, Park YG. Effects of low-level laser therapy after corticision on tooth movement and paradental remodeling. Lasers Surg Med. 2009;41:524-533.

115. Cassetta M, Altieri F, Pandolfi S, Giansanti M. The combined use of computer-guided, minimally invasive, flapless corticotomy and clear aligners as a novel approach to moderate crowding: A case report. Korean J Orthod. 2017;47:130-141.

116. Cassetta M, Altieri F, Barbato E. The combined use of corticotomy and clear aligners: A case report. Angle Orthod. 2016;86:862-870. 